\title{
Antibiotic resistance in uropathogenic enterobacteria
}

\author{
Jamila Hamamouchi ${ }^{1 *}$, Aicha Qasmaoui ${ }^{1}$, Karima Halout $^{1}$, Réda Charof $^{1}$, and Farida Ohmani $^{1}$ \\ ${ }^{1}$ Laboratory of Epidemic Diseases, Department of Medical Bacteriology, National Institute of Hygiene, Rabat, Morocco
}

\begin{abstract}
Multidrug-resistant Enterobacteriaceae are a major public health threat worldwide. These germs are the most redoubtable because they are producers of betalactamases and possess other mechanisms of resistance to many antibiotics. The objective of this work is to identify isolated strains of Enterobacteriaceae and to study their antibiotic resistance profiles, thus contributing to the surveillance of antibioresistance. This is a retrospective study over a period of three years (2018-2020) including urine samples taken in the region of Rabat-Salé-Zaire and examined at the laboratory of Epidemic Diseases in National Institute of Hygiene of Rabat. Enterobacteriaceae were the most frequent germs with a predominance of Escherichia coli $(68 \%)$ followed by Klebsiella pneumoniae $(23 \%)$. Extended-spectrum beta-lactamase-producing Enterobacteriaceae accounted for $10.5 \%$. The highest resistance was observed with amoxicillin, followed by ticarcillin, cefalotin, trimethoprim/sulfamethoxazole, amoxicillin+clavulanic acid, nalidixic acid and finally ciprofloxacin and norfloxacin. The aminoglycosides and the 2nd and 3rd cephalosporins were the most active molecules. The sensitivity of imipenem and ertapenem was $100 \%$. This study shows the worrying appearance of resistance to the usual antibiotics in uropathogenic enterobacteria. Rational prescription of antibiotics and monitoring of the evolution of bacterial resistance are necessary in each region. Keys words: Urinary tract infection, Enterobacteriaceae, Antibiotic resistance, Surveillance.
\end{abstract}

*Correspondingauthor: jhamamouchi@yahoo.fr 


\section{Introduction}

The remarkable efficacy of antibiotics has encouraged their overuse, leading to an increase in bacterial resistance to these molecules and the appearance of multi-resistant strains. These bacteria, essentially of hospital origin, have spread widely in the community, creating a major public health problem [1-5].

Multidrug-resistant bacteria (MRB) are defined as germs resistant to three or more antibiotics [1]. Their emergence is widely observed in urinary tract infections (UTI) [6,7]. These infections are among the most common, affecting individuals of different ages worldwide [8]. The most frequently detected MRBs, in order of frequency, are beta-lactamase enterobacteria, methicillin-resistant staphylococci and vancomycinresistant enterococci. These classes of bacteria can sometimes cause epidemics [9-11].

The increasing incidence of extended-spectrum betalactamase-producing Enterobacteriaceae (ESBLE), in many countries is an alarming situation. These gramnegative bacilli are not only resistant to most betalactamines antibiotics, but often have associated resistance to other classes of antibiotics used in human therapy, in particular fluoroquinolones, aminoglycosides and the sulfamethoxazole-trimethoprim [ 12]. Another group of bacteria has emerged in recent years. These are carbapenemase-producing strains of Enterobacteriaceae (CPE). These germs have become endemic in some localities. Resistance to carbapenems, which are still active compounds, is a worrying situation and constitutes an infectious threat towards a therapeutic impasse [13, $14]$.

In view of this perpetual increase in antibiotic resistance among Enterobacteriaceae, the fight against BMR must encourage health authorities to strengthen surveillance programs and promote research to develop other effective molecules. In this sense, our work aimed to determine the antibiotic resistance profiles of uropathogenic enterobacteria, isolated at the National Reference Laboratory of Epidemic Diseases, at the National Institute of Hygiene in Rabat. This is part of the laboratory's missions to strengthen the national surveillance system of antibiotic resistance, based mainly on laboratory data.

\section{Material and Methods}

\subsection{Type of study and strains studied}

This is a retrospective study over a period of three years (2018-2020) including all strains of Enterobacteriaceae isolated from urine samples taken in community settings in the Rabat-Salé-Zaire region. The samples were analyzed at the Laboratory of Epidemic Diseases at the National Institute of Hygiene in Rabat.

Each urine sample, in accordance with the criteria for acceptance and refusal of samples, underwent a urinary cytobacteriological examination (ECBU) including a uroculture, a microscopic examination to assess leukocyturia and other elements of the urine (red blood cells, crystals. . .).

\subsection{Identification and study of antibiotic sensitivity}

Urine samples were cultured and incubated for 24 hours at $37^{\circ} \mathrm{C}$ on Cystine Lactose Electrolyte Deficient Agar (CLED). After macroscopic observation of the colonies, the identification of the bacteria, based on the study of biochemical and enzymatic characteristics, was done by plating the API $20 \mathrm{E}{ }^{\circledR}$ galleries and reading after 24 hours of incubation.

The study of antibiotic susceptibility was performed by the diffusion technique on Muller Hinton agar plates. The reading and interpretation of the results were performed according to the guidelines of the Antibiogram Committee of the French Society of Microbiology (CASFM). The antibiotic molecules used for susceptibility testing were: amoxicillin (AMX); Amoxicillin+clavulanic acid (AMC); ticarcillin (TIC); cefalotin (CF); cefoxitin (FOX); cefotaxime (CTX); ceftazidime (CAZ); Amikacin (AK); gentamycin (GM); tobramycin (TOB); nalidixic acid (NA); norfloxacin (NOR); ciprofloxacin (CIP); trimeto-sulfamitoxazole (SXT); imipenem (IMP) and ertapenem (ETP).

Extended-spectrum beta-lactamase (ESBL)producing strains were tested by the synergy test between a central disc of amoxicillin + clavulanic acid and discs of 3rd generation cephalosporins $(\mathrm{C} 3 \mathrm{G})$. The notification of an ESBL is confirmed by the presence of a "champagne cork" aspect in a petri dish.

\subsection{Data collection}

The data involved all antibiograms performed from 2018 to 2020 and traced in the laboratory records. These results included, the name, age and gender of the patient. The identification number, origin and date of the sample are recorded. The germ identified and the antibiotics tested with their sensitivity profile are also reported.

The WHONET application, highly recommended by the WHO, was used for data management and analysis.

\section{Results}

During the study period, the laboratory received 2445 urine samples, 439 of which met the criteria for a urinary tract infection with a positivity rate of $17.9 \%$. Enterobacteriaceae were the most frequent germs, with 312 strains identified. Escherichia coli dominated the epidemiological profile (68\%) followed by Klebsiella pneumoniae $(23 \%)$ and other species with a rate of $9 \%$, including Klebsiella oxytoca, Enterobacter cloacae, Proteus mirabilis and Citrobacter freundii. The majority of positive cultures were from female patients $(86 \%)$ and adults (72\%).

ESBL production was observed in 33 isolates among 312 strains of enterobacteria, representing a prevalence of 
$10.5 \%$. The distribution of ESBL-secreting Enterobacteriaceae showed a total predominance of Escherichia and klebsiella with rates of $3.3 \%$ and $36.1 \%$, respectively (Table 1).

Table 1: Distribution of ESBL strains within the identified Enterobacteriaceae

\begin{tabular}{|l|l|l|l|}
\hline Strain & ESBL-E & $\begin{array}{l}\text { Number of } \\
\text { strains }\end{array}$ & $\begin{array}{l}\text { Percentage } \\
(\%)\end{array}$ \\
\hline E. coli & 07 & 212 & 3,3 \\
\hline K. pneumoniae & 26 & 72 & 36,1 \\
\hline Other species & 0 & 28 & 0 \\
\hline Total & 33 & 312 & 10,5 \\
& & & \\
\hline
\end{tabular}

E-BLSE: ESBL-producing Enterobacteriaceae; ESBL: Extended Spectrum Betalactamase.

Analysis of the susceptibility of non-ESBL producing strains to the antibiotics used revealed higher resistance to penicillins, 1st generation cephalosporins, trimethoprim/sulfamethazole, quinolones and fluoroquinolones. Carbapenems, aminoglycosides, 2nd and 3rd generation cephalosporins were the most active molecules against these uropathogens. Antibiotic resistance rates for the majority of strains isolated (E. coli and $K$. pneumoniae) are shown in Table 2.

UropathogenicEscherichia coli strains accounted for the largest number of all enterobacteria isolated. They were detected in outpatients. These strains showed significant rates of resistance to amoxicillin $(60.0 \%)$, followed by ticarciline (55.3\%), cefalotin (42.4\%), trimetho-sulfamethoxazole $\quad(37.6 \%), \quad$ amoxicillinclavulanic acid (34.1\%), nalidixic acid (29.0\%), ciprofloxacin (23.9\%) and norfloxacin $(20.6 \%)$. The sensitivity profile of $K$. pneumoniae was similar to that of E. coli. Both species showed $100 \%$ sensitivity to imipenem and ertapenem. Amikacin was the most effective molecule within the aminoglycoside class (97.6$100 \%)$.

In the case of ESBL-producing Enterobacteriaceae, we detected an increase in the resistance of the strains to the antibiotics tested. Co-resistance rates within the aminoglycoside class, quinolones and against Trimethosulfamithoxazole are reported in Table 3.

Resistance to antibiotics used in ESBL-producing $E$. coli was $42.0 \%$ for cipro-floxacin, $51.2 \%$ for trimethosulfamithoxazole, $23.7 \%$ for gentamicin and $19.5 \%$ for tobramicin. Amikacin and imipenem were 100\% effective. A similar profile was observed for $K$. pneomoniae ESBL. Resistance to amikacin did not exceed $8.5 \%$.
The table 4 represents the evolution of antibiotic resistance rates in E. coli, the most isolated germ between 2018 and 2020. An increase in antibiotic resistance was recorded mainly in the penicillin family (amoxicillin, ticarcillin and the amoxicillin-clavulanic acid). This observation was also noted with trimethosulfamethoxazole.

Table 2: Percentage (\%) of antibiotic resistance in isolated non-ESBL producing Escherichia coli and Klebsiella pneumoniae strains.

\begin{tabular}{|l|l|l|}
\hline Antibiotics used & $\begin{array}{l}\text { Escherichia } \\
\text { coli }\end{array}$ & $\begin{array}{l}\text { Klebsiella } \\
\text { pneumoniae }\end{array}$ \\
\hline Amoxicillin & 60,0 & 100 (NR) \\
\hline $\begin{array}{l}\text { Amoxicillin+clavulanic } \\
\text { acid }\end{array}$ & 34,1 & 32,7 \\
\hline Ticarcillin & 55,3 & 100 (NR) \\
\hline Imipenem & 0 & 0 \\
\hline Ertapenem & 0 & 0 \\
\hline Cefalotin & 42,4 & 34,5 \\
\hline Cefoxitin & 2,9 & 11,0 \\
\hline $\begin{array}{l}\text { Cefotaxime } \\
\text { /Ceftaxidime }\end{array}$ & 6,0 & 4,8 \\
\hline Amikacin & 0 & 2,4 \\
\hline Gentamycin & 5,4 & 10,1 \\
\hline Tobramycin & 7,2 & 11,3 \\
\hline Norfloxacin & 20,6 & 31,7 \\
\hline Ciprofloxacin & 23,9 & 25,0 \\
\hline Nalidixicacid & 29,6 & 27,2 \\
\hline Srimetho- \\
\hline sulfamethoxazole & 37,6 & 32,8 \\
\hline natural & & \\
\hline
\end{tabular}

NR : natural resistance

Table 3: Co-resistance profile to major antibiotics tested in ESBL-producing E. coli and K. pneumoniae strains

\begin{tabular}{|l|l|l|}
\hline Antibiotics tested & $\begin{array}{l}\text { E. coli } \\
\text { ESBL (\%) }\end{array}$ & $\begin{array}{l}\text { K. pneomoniae } \\
\text { ESBL (\%) }\end{array}$ \\
\hline Amikacin & 0 & 8,5 \\
\hline Gentamycin & 23,7 & 31,4 \\
\hline Tobramycin & 19,5 & 28,7 \\
\hline Ciprofloxacine & 42,0 & 50,3 \\
\hline $\begin{array}{l}\text { Trimetho- } \\
\text { sulfamithoxazole }\end{array}$ & 51,2 & 39,8 \\
\hline Imipenem & 0 & 0 \\
\hline
\end{tabular}


Table 4: Evolution of antibiotic resistance in Escherichia coli strains isolated between 2018 and 2020

\begin{tabular}{|l|l|l|}
\hline Antibiotics used & $\begin{array}{l}\text { Escherichia } \\
\text { coli (2018) }\end{array}$ & $\begin{array}{l}\text { Escherichia } \\
\text { coli (2020) }\end{array}$ \\
\hline Amoxicillin & $51 \%$ & $87,8 \%$ \\
\hline $\begin{array}{l}\text { Amoxicillin+clavulanic } \\
\text { acid }\end{array}$ & $22,6 \%$ & $41 \%$ \\
\hline Ticarcillin & $45,9 \%$ & $65,3 \%$ \\
\hline Cefalotin & $43,2 \%$ & $47 \%$ \\
\hline Ciprofloxacin & $23,7 \%$ & $24,2 \%$ \\
\hline Nalidixic acid & $30,5 \%$ & $31,3 \%$ \\
\hline $\begin{array}{l}\text { Trimetho- } \\
\text { sulfamethoxazole }\end{array}$ & $38,8 \%$ & $52,1 \%$ \\
\hline
\end{tabular}

\section{Discussion}

Urinary tract infections are a real public health problem. They are among the most common infections, affecting individuals of different ages worldwide. Their management has prompted many health institutions to issue guidelines and recommendations, with the aim of reducing the misuse of antibiotics and the risk of antibacterial resistance $[15,16]$. Their treatment is complicated by the emergence of antibiotic resistance. Resistance profiles of organisms differ between community-acquired and hospital-acquired UTIs [17].

The emergence and diffusion of multidrug-resistant bacteria in the different regions of the world require an update of the data and information provided by medical laboratories in coordination with their collaborators in each country. Indeed, the epidemiological profile of uropathogenic bacteria varies from one region to another [18-20]. Knowledge of the local epidemiology and its evolution would be essential for an appropriate and adequate first-line antibiotic therapy for each region

Our study has shown that the epidemiology of community-acquired UTIs is generally in line with the national and global literature regarding age, sex and the germ most involved in this pathology, which is E. coli. This bacterium has often dominated the epidemiological profile in both hospital and community settings [21-23].

We recorded a positive rate of $17.9 \%$ for ECBU. These samples were taken in outpatient clinics. This rate being similar, compared to other national works that shared percentages ranging from $13.3 \%$ to $23 \%$ [24,25]. It has been reported that community-acquired urinary tract infections are the most frequent in relation to hospital-acquired infections [26, 27].

Enterobacteriaceae accounted for $71 \%$ of all isolates with E. coli $(68 \%)$ as the majority specie. Klebsiella pneumoniae, in second place, was also implicated in these UTIs with a considerable rate of $23 \%$. This result is in agreement with other scientific citations with variable rates [28-30]. The predominance of these gram-negative bacilli is well elucidated by their uropathogenic character (adhesins, urease...) and the ascending pathophysiology of
UTI from the urethral flora (colonization of the perineum by enterobacteria of digestive origin) [31].

Among isolated enterobacteria, we reported a rate of $10.5 \%$ of ESBL-E. This prevalence differs from place to place. Nationally, rates ranging from 4.5 to $12.2 \%$ have been reported [24, 32]. Other foreign countries have reported rates ranging from 8.2 to $34.7 \%[33,34]$. These studies excluded the strict hospital affiliation of these strains.

According to our results, the prevalence rate of ESBL in the community, recorded at $10.5 \%$, remains worrying in view of the probable spread of its multidrug-resistant strains. Klebsiella ESBL occupied the first position with $36.1 \%$ of isolates. Indeed, this species has been shown to be the most productive of these betalactamases with varying rates [27, 34]. However, in a study in Pakistan, $E$. coli specie came close to Klebsiella pneumoniae in the production of extended-spectrum $\beta$-lactamases (ESBL) with respective rates of $66.2 \%$ and $64.4 \%$ [35]. Another Colombian study attributed the predominance of this ESBL phenotype to $E$ coli $(93.2 \%)$, followed by $K$. pneumoniae $(5.2 \%)$. Other species, $K$. oxytoca and $P$. mirabilis were also ESBL producers with a rate not exceeding $0.8 \%$ [36].

The study of the sensitivity of uropathogenic enterobacteria to antibiotics has shown a high level of resistance to the majority of the molecules tested. The same observation has been reported by authors in other countries. This phenomenon is mainly due to the massive use of large spectrum antibiotics. The cross-transmission of acquired plasmid resistance is also incriminated in the dissemination of this resistance [37-39].

Antibiotic resistance of E. coli strains, the bacillus most involved in hospital and community UTIs, has highlighted variable and high rates of resistance to the antibiotics used and mainly to the main molecules prescribed for the treatment of these infections. Indeed, our laboratory has detected high rates of resistance of $E$. coli against penicillins, mainly amoxicillin and ticarcillin with respective percentages of $60.0 \%$ and $55.3 \%$. High rates of resistance against amoxicillin and ticarcillin were also shared by other studies [40,41]. The high level of resistance to amoxicillin in uropathogenic $E$. coli justifies the use of this antibiotic in combination with clavunalic acid (AMC). However, the resistance acquired by bacteria against this molecule has become a worldwide fact. The rate of resistance recorded during our investigation was $34.1 \%$ and $32.7 \%$ against $E$. coli and $K$. pneumoniae, respectively. Significant and varied rates have also been reported in the literature [42, 43].

Other molecules are prescribed for the treatment of certain urinary tract infections, namely the fluoroquinolone class. However, the increase in their use has been accompanied by an increase in bacterial resistance [8]. The rate of $E$. coli resistance to ciprofloxacin found in our study was $23.9 \%$. Other strains of the same species showed a resistance to this fluroquinolone of $54.1 \%$ [44]. Resistance to quinolones has also been increasingly identified in uropathogenicE. coli. The susceptibility profile to the usual antibiotics revealed that the highest rates of resistance were to nalidixic acid ranging from $69.3 \%$ to $81 \%[45,46]$. In our case, this substance had 
underwented a resistance of $29,6 \%$ and $27.2 \%$ by E. coli and K. pneumoniae, respectively.

Compared to our study, the rate of resistance to trimethro $\neg$ pime-sulfamethoxazole has marked important values both in hospital and community settings [27, 47]. The epidemiological situation of resistance against STX fluctuates between $32.8 \%$ and $37.6 \%$ with our strains of $K$. pneumoniae and E. coli, respectively.

The class of aminoglycosides showed an appreciable activity with amikacin. With gentamicin, the resistance did not exceed $5.4 \%$ with $E$. coli and $10.1 \%$ with $K$. pneumoniae. However, this molecule showed a high resistance rate of $52.3 \%$ and $68 \%$ against uropathogenic enterobacterial isolates in an Indian and Ethiopian study, respectively [48, 49].

The sensitivity to 3rd generation cephalosporins was remarkable for the majority of enterobacteria isolated in our laboratory. However, other literature data revealed a high percentage of resistance. This high rate is related to the considerable number of $E$. coli and other uropathogenic germs, producers of ESBL $[24,32]$. In our study, the systematic search for ESBLs showed cases of this phenotype exclusively in E. coli and K. pneumoniae. This phenomenon has also been reported in studies conducted in Saudi Arabia, Etyopia and Europe [39, 50, 51]. Antibiotic resistance in ESBL-producing strains of $E$. coli and $K$. pneunomiae has shown higher rates of resistance to many antibiotics compared to non-ESBLproducing strains. This phenomenon could be explained by the fact that ESBL genes, usually carried by plasmids, are often associated with antibiotic resistance genes, especially to aminoglycosides, fluoroquinolones and Trimetho-sulfamithoxazole [32].

Regarding the carbapenem class, no resistance to imipenem or ertapenem was recorded for the collected strains. This finding is similar to a study that was conducted in Pakistan to determine the correlation between antibiotic susceptibility and drug prescription in the empirical treatment of uropathogenic E. coli. All isolates were susceptible to imipenem [52]. However, judicious use of this molecule is imperative to prevent the emergence of carbapenemase-producing strains.

The increase in the prevalence of ESBL strains in community urinary tract infections exposes the risk of an increase in the prescription of penems. This class of antibiotics must be protected while favouring alternatives. We mention the use of other molecules such as the pipiracillin-tazobactam combination [53]. Another study suggested that fosfomycin and nitrofurantoin could be an excellent therapeutic option for UTIs [20, 49, 54]. In Morocco, fosfomycin has shown promising in vitro activity against multidrug-resistant urinary tract infections [24]. This molecule still has good activity due to its low prescription, although it is highly recommended for the treatment of uncomplicated UTIs. The combination of amikacin and amoxicillin/clavulanate could also be recommended as an alternative to carbapenem in patients with acute cystitis caused by ESBL-producing enterobacteria [55]. Another therapeutic alternative to carbapenems has been proposed for the treatment of ESBL-producing enterobacteria. Indeed, according to the new recommendations of the Antibiogram Committee of the French Society of Microbiology for the interpretation of antibiograms, C3G and $\mathrm{C} 4 \mathrm{G}$ could be classified as sensitive against ESBLproducing strains, after determination of their minimum inhibitory concentrations.

Overall, our study provided an indication of the level of resistance to the usual antibiotics. We noted resistance to penicillins, $1 \mathrm{st}$ generation cephalosporins, trimethoprim/sulfamethazole, quinolones and fluoroquinolone. These molecules are widely used in the treatment of UTIs. In ESBL-E, our results are in agreement with epidemiological data from other countries, with more moderate rates. Except for amikacin, we noted a low level of resistance of about $8.5 \%$. These ESBL-E are generally resistant to antibiotics used in urology.

The increased prevalence of resistance in community and hospital urinary tract infections confirms the notion of selection pressure due to the excessive prescription and sometimes abusive use of large spectrum antibiotics (selfmedication, sale of antibiotics without prescription by pharmacies, etc.). In addition, the increasing use of antibiotics in agriculture and animal husbandry could have a considerable effect on the increase in the level of antimicrobial resistance.

\section{Conclusion:}

Antibiotic resistance in urinary tract infections (UTIs) is a public health problem that ranks among the world's greatest medical emergencies. However, estimates of the prevalence of resistance to these substances, necessary for treatment guidelines, are lacking in many regions.

This retrospective study spread over a period of 3 years in the region of Rabat, revealed the strong involvement of Enterobacteriaceae in community urinary tract infections and that the leading causative pathogen was Escherichia coli followed by Klebsiella pneumoniae. This investigation also noted a not negligible prevalence of ESBL-E (10.5\%). A significant level of co-resistance was detected to antibiotics used in UTIs such as ciprofloxacin, gentamicin and trimethosulfamethoxazole. Amikacin was the most active molecule. Carbapenems, $\beta$-lactamins used for last-line treatment, had a sensitivity of $100 \%$.

The increasing resistance of community strains of $E$ coli to antibiotics has become an alarming phenomenon in Morocco. This calls for serious reflection on the management of UIs, through therapeutic consensus taking into account the national epidemiological situation of antibiotic resistance provided regularly by surveillance studies.

In addition, laboratory surveillance of antibiotic resistance, an essential component of health system strengthening, must be expanded as it is useful for improving care delivery as well as for disease prevention and control. Accurate, reliable, and timely laboratory testing is essential in the overall surveillance scheme. 
These laboratoriesmust house trend analyses ranging from susceptibility testing, to searching for resistance genes, to molecular typing of resistant strains. Only early detection of these emerging resistances can help limit their propagation and optimize antibiotic management.

On the basis of the sensitivity profiles of uropathogenic enterobacteria to the tested antibiotics, molecules could be proposed and considered as a first therapeutic choice to treat urinary infections in the Rabat region. Frequent and targeted surveillance of antibioticresistant pathogens and the study of their susceptibility profiles are essential to allow a probabilistic treatment adapted to patients. Rational prescription of antibiotics and respect of hygiene measures are also necessary to limit the evolutionary and worrying character of antibiotic resistance of uropathogenic germs.

\section{Références}

1. S. Nseir, F. Ader, C.H. Marquette, D.A. Durocher, Pathol. Biol. 53, 470-475 (2005)

2. M. Lagree, S. Bontemps, R. Dessein, F. Angoulvant, F. Madhi, A. Martinot, R. Cohen, F. Dubos, Med. Mal. Infect. 48, 193-201 (2018)

3. A. Mitiku, A. Aklilu, G. Biresaw, A. Gize, Infect. Drug. Resist. 14, 2133-2142 (2021)

4. M. Arisa Castro Jara, A. Vieira Frediani, F. Knepper Zehetmeyer, F. Raphael Pascoti Bruhn, M. Ribeiro Müller, R. Giusti Miller, Microb. Drug Resist. 27, 433-440 (2021)

5. T. Eigenbrod, S. Reuter, A. Gross, K. Kocer, F. Günther, S. Zimmermann, K. Heeg, N.T. Mutters, D. Nurjadi, J.Antimicrob. Chemother, 74, 3473-3480 (2019)

6. A. A. Elshamy, K. M. Aboshanab, M. A. Yassien, N. A. Hassouna, Afr. Health Sci.20, 190-198 (2020)

7. Norafika, N. Arbianti, S. Prihatiningsih, D. W. Indriani, Germs, 10 , 157-166 (2020)

8. H. A. Amawi, H. T. U'wais, M. B. Nusair, R. AlOkour, S. Amawi, S. Al-Shatnawi, A. Abdi, Int J Clin Pract.e14475 (2021)

9. D. Vodovar, G. Marcadé, L. Raskine, I. Malissin, B. Mégarbane, Rev Med Interne. 34, 687-93 (2013)

10. P. Saengsuwan, K. Singkhamanan, S. Madla, N. Ingviya, C. Romyasamit, Peer J. 20, 11478 (2021)

11. S. V. Kotov, S. A. Pulbere, N.V. Alesina, V.S. Boyarkin, R. I. Guspanov, S.V. Belomytsev, D. P. Kotova, Urologiia, 1, 5-12 (2021)

12. Y. H. Chen, W. C. Ko, P. R. Hsueh, Expert Opin. Pharmacother., 14, 587-96 (2013)

13. J.C. Lucet, G. Birgand, Journal des anti-infectieux 13, 122-132 (2011)

14. G. Perletti, V. Magri, T. Cai, K. Stamatiou, A. Trinchieri, E. Montanari, Arch Ital Urol Androl. 90, 85-96 (2018)

15. A. Piraux, S. Faure, K.G. Naber, J.F. Alidjanov, A. Ramond-Roquin, BMC Health Serv Res. 21, 612 (2021)

16. H. A. Amawi, H. T. U'wais, M. B. Nusair, R. AlOkour, S. Amawi, S. Al-Shatnawi, A. Abdi, Int J Clin Pract. e14475 (2021)
17. H. Akhavizadegan, H. Hosamirudsari, H. Pirroti, S. Akbarpour, East Mediterr Health J. 27, 124-130 (2021)

18. M.C.El Bouamri, L. Arsalane, Y. Kamouni, M. Berraha, M. S. Zouhair, Prog Urol. 24451-5 (2014)

19. E. Serretiello, V. Folliero, B. Santella, G. Giordano, E. Santoro, F. De Caro, P. Pagliano, M. Ferro, S. M. Aliberti, M. Capunzo, M. Galdioro, G. Franci, G. Boccia, Int J Microbiol. 21,5541706 (2021)

20. J. Artero-López, B. Gutiérrez-Soto, M. ExpósitoRuiz, A. Sorlózano-Puerto, J. M. Navarro-Marí, J. Gutiérrez-Fernández, J. ,rch Esp Urol. 74, 197-207 (2021)

21. M. Gajdács, M. Ábrók, A. Lázár, K. Burián, Medicina $\mathbf{5 5 , 3 5 6}$ (2019)

22. V. Zanichelli, A. Huttner, S. Harbarth, A. Kronenberg, B. Huttner, Swiss Med Wkly. 24, 149 (2019)

23. A. K. Sugianli, F. Ginting, I. Parwati, M. D. de Jong, F. van Leth, C. Schultsz, JAC Antimicrob Resist. 3, (2021)

24. M. Sbiti, K. Lahmadi, L. Louz, Pan Afr Med J.28, 29 (2017)

25. H. Zahir, G. Draiss, N. Rada, A. Abourrahouat, I. Aitsab, M. Sbihi, M. Bouskraoui, N. Soraa, Revue Francophone des Laboratoires,511, 65-70 (2019)

26. A. Lahlou, M. Chegri, H. L. Kassmi, Antibiotiques, 11, 90-96 (2009)

27. N. S. M. Hailaji, M. L. Ould Salem, S. M. Ghaber, Prog Urol.26, 346-52 (2016)

28. G. Ziółkowski, I. Pawłowska, M. Stasiowski, E. Jachowicz, J. Wójkowska-Mach, T. Bielecki, Antibiotics, 10, 7 (2020)

29. S. Larramendy, V. Deglaire, P. Dusollier, J. P. Fournier, J. Caillon, J. F. Beaudeau, L. Moret, Infect Drug Resist. 13,3945-3955 (2020)

30. Y. M. Ndzime, R. Onanga, R. F. Kassa, M. Bignoumba, P. M. Nguema, A. Gafou, R. W. Lendamba, K. M. Moghoa, C. Bisseye, Infect Drug Resist.14, 585-594 (2021)

31. H. Ben Abdallah, O .Sahnoun, F. Ben Romdhane, M. Mastouri, Rev. Tun Infectiol. , 2, 5 - 8 (2008)

32. M. C. El Bouamri, L. Arsalane, Y. Kamouni, H. Yahyaoui, N. Bennouar, M. Berraha, S. Zouhair, Prog Urol, 24,1058-62 (2014)

33. F. Gravey, G. Loggia, A. de La Blanchardière, V. Cattoir, Med Mal Infect. 47, 271-278 (2017)

34. C. Baizet, S. Ouar-Epelboin, G. Walter, E. Mosnier, B. Moreau, F. Djossou, L. Epelboin, Med Mal Infect.49,63-68 (2019)

35. N. Humera, A. Mubashar, A. M. Zulfiqar, A. S. Sheikh, M. Q. Saeed, A. Khan, T. Ruby, N. Rauf, Iran J Basic Med Sci, 24, 400-407 (2021)

36. J. C. Cruz, J. M. Martinez, J. M. Cufino, G. C. Moreno, C. R. Murillo, M. A. Suarez Fuentes, C. A. Castro, Indian Pediatr, 58,144-148 (2021)

37. A. Ferjani, H. Mkaddemi, S. Tilouche, M. Marzouk, N. Hannechi, L. Boughammoura, Arch Pediatr. 18, 230-4 (2011)

38. E. Launay, E. Bingen, R. Cohen, Arch Pediatr.19, 109-16 (2012) 
39. A. S. Bazaid, A. Saeed, A. Alrashidi, A. Alrashidi, K. Alshaghdali, S. A. Hammam, T. Alreshidi, M. Alshammary, A. Alarfaj, R. Thallab, A. Aldarhami, Infect Drug Resist.14,1455-1465 (2021)

40. A. A. Al-Naqshbandi, M. A. Chawsheen, H. H. Abdulqader, J Infect Public Health, 12, 330-336 (2019)

41. S. Guermazi- Toumi, S. Boujlel, M. Assoudi, R. Issaoui, S. Tlili, M. E. Hlaiem, J Glob Antimicrob Resist. 12, 48-52(2018)

42. E. Mantadakis, E. K. Vouloumanou, M. Panopoulou, E. Tsouvala, A.Tsalkidis, A. Chatzimichael, M. E. Falagas, J Glob Antimicrob Resist. 3, 85-90 (2015)

43. J. A. Karlowsky, P. R. Lagacé-Wiens, H. J. Adam, M. R. Baxter, N. M. Laing, A. J. Walkty, G. Zhanel, Int J Antimicrob Agents, 54, 62-68 (2019)

44. S. V. Kotov, S. A. Pulbere, N. V. Alesina, V. S. Boyarkin, R. I. Guspanov, S. V. Belomytsev, D. P. Kotova, Urologiia, 1, 5-12 (2021)

45. A. Sadeghi, M. Halaji, A. Fayyazi, S. A. Havaei, Biomed Res Int. 27, (2020)

46. A. Matalka, N. Al-Husban, O. Alkuran, L. Almuhaisen, A. Basha, M. Eid, M. S. Elmuhtaseb, K. Al Oweidat, J Int Med. 49,(2021)

47. H. Caskurlu, M. Culpan, B. Erol, T. Turan, H. Vahaboglu, T. Caskurlu, Urol Int. 104, 287-292, (2020)
48. Y. A. Gessese, D. L. Damessa, M. M. Amare, Y. H. Bahta, A. D. Shifera, F. S. Tasew, E. Z. Gebremedhin, Antimicrob Resist Infect Control, 29, 6:132 (2017)

49. S. Sreenivasan, A. Kali, M. V. Pravin Charles, S. Kunigal, J Lab Physicians 11, 249-252 (2019)

50. K. Vazouras, Y. Hsia, L. Folgori, J. Bielicki, E. Aguadisch, A. Bamford, A. Brett, M. Caseris, R. Cerkauskiene, M. DeLuca, E. S. Iosifidis, J. Kopsidas, A. Manzanares, T. Planche, A. Riordan, T. P. Srovin, Pediatr Infect Dis J. 39, 1081-1087 (2020)

51. D. Kasew, S. Eshetie, A. Diress, Z. Tegegne, F. Moges, BMC Urol. 21, 27(2021)

52. G. Ali, S. Riaz-Ul-Hassan, M. A. Shah, M. Q. Javid, A. R. Khan, L. Shakir, J Pak Med Assoc. 70, 2039$2042(2020)$

53. J. Álvarez, A. Rojas, C. Carvajal, J. Revello, P. Meza, P. Guggiana, P. García, J. Labarca, Rev Chilena Infectol. 35, 343-350(2018)

54. H. Y. Liu, H. C. Lin, Y. C. Lin, S. H. Yu, W. H. Wu, Y. J. Lee, J Microbiol Immunol Infect. 44, 364-368 (2011)

55. S. T. Ahn, D. E. Han, D. H. Lee, J. W. Kim, H. S. Park, D. G. Moon, M. M. Oh, Investig, Clin Urol.62, 310316 (2021) 